\title{
The use of electrolytic conductivity in breeding sugar beet for quality
}

\author{
B Schweisguth, JP Denizot \\ INRA, Station de Génétique et d'Amélioration des Plantes, BV 1540, F21034 Dijon Cedex, France
}

(Received 20 December 1992; accepted 19 April 1993)

\begin{abstract}
Summary - Sugar beet varieties from 2 trials (1990 and 1991) were analysed for quality. Pulp samples were analysed for $\mathrm{K}^{+}, \mathrm{Na}^{+}, \alpha$-amino nitrogen, glucose and polarimetric sugar (sucrose). The electrolytic conductivity of the samples was measured. In both trials, 1990 and 1991, conductivity was positively correlated with $\mathrm{K}^{+}(r=0.7$ and 0.8$), \mathrm{Na}^{+}$ $(r=0.5$ and 0.2$), \alpha$-amino nitrogen $(r=0.2$ and 0.6$)$ and molasse sugar $(r=0.3$ and 0.7$)$. It was negatively correlated with sucrose $(r=-0.3$ and -0.6$)$ and glucose $(r=-0.4$ and -0.3$)$. The variation of electrolytic conductivity was explained by a multiple regression equation with different independent variables according to the trial: $\mathrm{K}^{+}$, glucose, $\mathrm{Na}^{+}$, sucrose in 1990, with $R^{2}=0.65$ and $\mathrm{K}^{+}$, sucrose, $\alpha$-amino nitrogen, glucose in 1991 , with $R^{2}=0.81$. Genotypic $\left(r_{G}\right)$ and micro-environmental (residual) $\left(r_{\mathrm{e}}\right)$ correlations were computed for conductivity and the other traits. $r_{\mathrm{G}}$ had a high absolute value for: sucrose $(-0.68), \mathrm{K}^{+}(0.71), \mathrm{Na}^{+}(0.71)$ and glucose $(-1.15)$, but was medium for molasse sugar $(0.50)$. Selection for low conductivity should be efficient in improving quality only if a large variability exists among genotypes for cation concentration.
\end{abstract}

sugar beet / electrolytic conductivity / molasses sugar / phenotypic correlation / genotypic correlation

Résumé - Utilisation de la conductivité électrique pour l'amélioration de la qualité de la betterave à sucre. Des analyses ont été faites sur les variétés de 2 essais de betterave à sucre, en 1990 et 1991, pour évaluer leur qualité technologique. Les éléments suivants ont été analysés sur des échantillons de râpure : les cations $\mathrm{K}^{+}$et $\mathrm{Na}^{+}$, l'azote $\alpha$-aminé, le glucose et le sucre polarimétrique (saccharose). Le sucre mélasse - la part non extractible du saccharose - a été calculé avec une formule de IIIRIS. Parallèlement, la conductivité électrique a été mesurée sur chaque échantillon. La conductivité est corrélée positivement, en 1990 et 1991, avec la concentration en cations ( $\mathrm{r}=0,7$ et 0,8 pour $\mathrm{K}^{+}, 0,5$ et 0,2 pour $\left.\mathrm{Na}^{+}\right)$, avec l'azote $\alpha$-aminé $(\mathrm{r}=0,2$ et 0,6$)$ et le sucre mélasse $(\mathrm{r}=0,3$ et 0,7$)$. Elle est corrélée négativement avec le sucre polarimétrique $(r=-0,3$ et $-0,6)$ et le glucose $(r=-0,4$ et $-0,3)$. La variabilité de la conductivité est expliquée par une équation en régression multiple comportant des variables explicatives différentes selon l'essai : $\mathrm{K}^{+}$, glucose, $\mathrm{Na}^{+}$, saccharose en 1990 , avec $\mathrm{R}^{2}=0,65$ et $\mathrm{K}^{+}$, saccharose, azote $\alpha$-aminé, glucose en 1991 , avec $\mathrm{R}^{2}=0,81$. Des analyses de variance et covariance sur l'essai de 1991 ont permis d'estimer les corrélations génotypiques $\left(\mathrm{r}_{G}\right)$ et micro-environnementales (résiduelles) $\left(\mathrm{r}_{\mathrm{e}}\right.$ ) entre la conductivité et les éléments de la qualité. Les $\mathrm{r}_{G}$ sont importantes pour le saccharose $(-0,68), K^{+}(0,71), \mathrm{Na}^{+}(0,71)$ et le glucose $(-1,15)$, mais pour le sucre mélasse $\mathrm{r}_{G}$ est moyen $(0,50)$. La sélection pour une faible conductivité ne conduira à un progrès de la qualité que dans le cas d'une forte variabilité des génotypes pour la concentration en cations.

betterave à sucre / conductivité électrique / sucre mélasse / corrélation phénotypique / corrélation génotypique

\section{INTRODUCTION}

Sugar-beet quality is of prime importance to the sugar processing industry. A part of the sucrose contained in the beet juice is not extractable and is lost to the molasses; this is the molasse sugar, and is due to non-sucrose constituents, the so-called impurities. Sugar-beet quality can be expressed as the percentage of molasse sugar which depends on the content of the $\mathrm{K}^{+}$ and $\mathrm{Na}^{+}$cations, of free $\alpha$-amino-nitrogen and glucose (Devillers, 1988). The recoverable sugar is the difference between the total sugar content of the root and the molasse sugar.

This quality is affected by both genotype and crop management (fertilizer rate, plant spacing harvesting date) (Smith et al, 1977). Environmental factors are often more important than 
genotype in affecting quality (Bruandet et al, 1990). Nevertheless, plant breeders in Europe are urged to select for high quality. They have to analyse thousands of samples of individual roots, lines and hybrids each year to measure their sugar content and assess their quality. The necessary analyses are expensive, although they can be totally automated. In the early stages of breeding a simpler and cheaper measurement would be welcome.

Rearick and Schoenrock (1985) introduced electrolytic conductivity as an easy-to-perform measurement to assess the quality of sugar beet roots entering the factory. They found a high negative correlation between conductivity and synthetic thin juice purity: $r=0.933$ for $\approx 1200$ samples. The best coefficients were obtained when conductivity was measured on the fresh pulp or the expressed juice.

Conductivity is also used by Australian sugarcane breeders to estimate ash impurities in sugar-cane expressed juice (Berding et al, 1991).

The objective of the present work was to evaluate whether electrolytic conductivity could be used to breed sugar beet for quality, ie with a higher percentage of recoverable sugar.

Conductivity and contents of the cations and of the compounds contributing to molasses sugar were measured on pulp samples from 2 variety trials.

\section{MATERIALS AND METHODS}

Two variety trials were used: in 1990 , a $7 \times 7 \times 4$ lattice design with 49 varieties, 3 cultivars (Regina, Accord, Massabel) and 46 experimental diploid hybrids ; in 1991, a $5 \times 5 \times 4$ lattice design with 25 varieties, 4 cultivars (Rizor, Accord, Aramis, Massabel) and 21 experimental diploid hybrids. In both years the elementary plot consisted of $36.75-\mathrm{m}$ long rows with $0.5 \mathrm{~m}$ between the rows. The 3 rows were harvested. The target stand was 92000 plants $h^{-1} a^{-1}$ Sowing date, fertilizer rates and pesticide treatments were those currently used by sugar-beet growers. Mean total sugar yields were good: $12.18 \mathrm{~T} \cdot \mathrm{ha}^{-1}$ in 1990 and 12.54 $\mathrm{T} \cdot \mathrm{ha}^{-1}$ in 1991.

The following traits were measured on pulp samples from the plots of only 3 replicates in both years, and of only 47 varieties in 1990 :

$-C$ electrolytic conductivity, in $\mathrm{mS} \cdot \mathrm{cm}^{-1}$;

$-S$ polarimetric sugar in percent fresh weight. Polarimetric determination of sucrose is routinely used in many laboratories although other organic constituents of the juice are optically active. Polarimetric sugar has been considered equal to sucrose in this study.

- $K$ and $\mathrm{Na}, \mathrm{K}^{+}$and $\mathrm{Na}^{+}$contents, respectively, in mmol for $100 \mathrm{~g}$ fresh weight;

- G glucose, in percent fresh weight;

Conductivity was measured at Dijon, with a conductivity meter equipped with a probe specially designed for pulp or whole roots. Measures were taken on defrozen pulp in 1990 and on fresh pulp in 1991. The 5 other analyses were made at IRIS (the Institut de Recherche de l'Industrie Sucrière) on defrozen pulp.

Ms, molasses sugar, was estimated by the formula established by IRIS (Devillers, 1988):

$M s=0.14(K+N a)+0.25 N+3.3 G+0.30$, and was expressed in percent fresh weight of root.

Correlation coefficients were computed between $C$ and the other traits on per plots values. They are estimates of the phenotypic correlations.

Multiple regression equations and multiple correlation coefficients were then computed on the same basis, $C$ being the dependent variable and the other traits the independent variables. The stepwise procedure of the SAS computer system was used.

Analysis of variance was applied to all traits in both trials as randomized block designs with 3 replicates. The F-test showing no significant varietal differences in the 1990 trial; analysis of covariance was applied to the 1991 trial only, to estimate genotypic correlations and correlations between residues (microenvironmental effects). The genotypic correlations were computed as:

$$
r_{\mathrm{G} 12}=\frac{M P_{12}-M P_{\mathrm{e} 12}}{\sqrt{\left(M S_{1}-M S_{\mathrm{e} 1}\right)\left(M S_{2}-M S_{\mathrm{e} 2}\right)}}
$$

where: $M P_{12}$ : mean product of traits $1 \times 2$, for varieties; $M P_{\mathrm{e} 12}$ : mean product of traits $1 \times 2$, for residues; $M S_{1}\left(M S_{2}\right)$ : mean square of trait 1 (2), for varieties; $M S_{\mathrm{e} 1}\left(M S_{\mathrm{e} 2}\right)$ : mean square of trait $1(2)$, for residues. The micro-environmental correlations were computed as:

$$
r_{\mathrm{e}}=\frac{M P_{\mathrm{e} 12}}{\sqrt{M S_{\mathrm{e} 1} \times M S_{\mathrm{e} 2}}}
$$

There is no direct test of signicance for these coefficients (Gallais, 1990).

We have computed these coefficients only for $C$ as variable 1 and the other variables each as variable 2 . Variance and covariance analysis were carried out using AMANCE software.

The varieties cannot be considered as a random sample from a population, so the computed $r_{G}$ do not have the meaning of a genetic correlation. They are rather estimations of the contribution of the varieties, in this particular trial, to the correlation between $C$ and the other traits. 


\section{RESULTS}

Phenotypic correlation coefficients between $C$ and $S, K, N a, N, G$ and $M S$ are presented in table I.

All coefficients were significant at the 0.001 level in 1990. In 1991, there was no correlation between $C$ and $\mathrm{Na}$. The coefficient for $C \times G$ was significant at the 0.01 level, the other 4 at the 0.001 level.

Conductivity was negatively correlated with polarimetric sugar and glucose. It was positively correlated with $\mathrm{K}^{+}, \mathrm{Na}^{+}$and the $\alpha$-aminonitrogen.

Table I. Correlation coefficients between conductivity and polarimetric sugar $(S)$, the cations $\mathrm{K}^{+}(K)$ and $\mathrm{Na}^{+}$ (Na), $\alpha$-amino nitrogen $(N)$, glucose $(G)$ and molasses sugar (Ms) in 2 variety trials, computed on per plot values.

\begin{tabular}{lrc}
\hline & 1990 & $1991^{-}$ \\
\hline$S$ & $-0.345^{\star \star}$ & $-0.587^{\star *}$ \\
$K$ & $0.693^{\star \star}$ & $0.807^{\star \star}$ \\
$N a$ & $0.539^{\star \star}$ & $0.219^{\star *}$ \\
$N$ & $0.233^{\star *}$ & $0.615^{\star *}$ \\
$G$ & $-0.360^{\star *}$ & $-0.303^{\star}$ \\
$M S$ & $0.337^{\star *}$ & $0.741^{\star *}$ \\
\hline
\end{tabular}

1990: $n=141 ; 1991: n=75 ;{ }^{*}$ significant at the 0.01 level; ** significant at the 0.001 level.
The parameters of the multiple regression equaton of $C$ on the elements of molasses sugar (Ms) and $S$ appear in table II.

Conductivity variability was not explained by the same variables in both trials, although $K$ was always in the first rank. G ranked 2nd in 1990 and 4th in 1991, S 4th in 1990 and 2nd in 1991. $\mathrm{Na}$ was in the 3rd position in 1990 but was excluded in 1991, its contribution being not significant. Exactly the reverse was true for $N$.

The regression model with 4 independent variables (a different set each year) explained a medium to high proportion of the variability, $R^{2}$ values reaching 0.65 and 0.81 in 1990 and 1991 , respectively. The multiple correlation coefficients were 0.80 and 0.90 in 1990 and 1991, respectively.

Variance analysis was applied to both trials. The results are summarized in table III.

In the 1990 trial the varieties were significantly different for $\mathrm{Na}$ only. No other statistical analyses was carried out.

In the 1991 trial varietal differences were significant for several traits: $N a$ at the 0.05 level, $C$, $S, K$ and $G$ at the 0.01 level, but not for $N$ and Ms. A covariance analysis was then performed for $C$ and all other traits. The results are summarized in table IV.

Both genotypic $\left(r_{\mathrm{G}}\right)$ and environmental $\left(r_{\mathrm{e}}\right)$ correlation coefficients were negative and relatively high for $C$ and $S$. They were positive and high for $C$ and $K$. For the other traits $r_{\mathrm{G}}$ and $r_{\mathrm{e}}$ were very different:

Table II. Multiple regression equations for conductivity with $\mathrm{K}^{+}(\mathrm{K}), \mathrm{Na}^{+}(\mathrm{Na}), \alpha$-amino nitrogen $(\mathrm{N})$, glucose $(\mathrm{G})$ and polarimetric sugar (S) as independent variables.

$\begin{array}{lrrrrrr}\text { Variables entered in model } 1990 & \text { Parameter estimate } & \text { F } & \text { Probability } & \text { Model R } & \text { F } & \text { Probability } \\ & & & & & & \\ \text { K } & & & & & & \\ \text { G } & 0.3132 & 97.28 & 0.0001 & 0.481 & 128.71 & 0.0001 \\ \text { Na } & -2.7461 & 17.01 & 0.0001 & 0.577 & 31.39 & 0.0001 \\ S & 0.6241 & 19.54 & 0.0001 & 0.629 & 19.24 & 0.0001 \\ \text { Intercept } & -0.0567 & 6.87 & 0.0098 & 0.647 & 6.87 & 0.0098 \\ & 1.4943 & 9.74 & 0.0022 & & & \\ \text { 1991 } & & & & & & \\ K & & & & & & \\ S & 0.3224 & 52.97 & 0.0001 & 0.651 & 136.12 & 0.0001 \\ N & -0.1891 & 35.66 & 0.0001 & 0.767 & 35.95 & 0.0001 \\ G & 0.3772 & 12.81 & 0.0006 & 0.798 & 10.97 & 0.0015 \\ \text { Intercept } & -4.2138 & 4.15 & 0.0455 & 0.810 & 4.15 & 0.0455\end{array}$


Table III. Analysis of variance of 2 variety trials for conductivity $(C)$, polarimetric sugar $(S), K^{+}(K), \mathrm{Na}^{+}(\mathrm{Na}), \alpha$-amino nitrogen $(N)$, glucose $(G)$ and molasses sugar $(M s)$. MS = mean square.

\begin{tabular}{|c|c|c|c|c|c|c|c|}
\hline & & \multicolumn{3}{|c|}{1990} & \multicolumn{3}{|c|}{1991} \\
\hline & & $R e p$ & Var & Error & $R e p$ & Var & Error \\
\hline c & $\begin{array}{l}M S \\
F\end{array}$ & $\begin{array}{l}0.137 \\
3.644^{\star}\end{array}$ & $\begin{array}{l}0.043 \\
1.147\end{array}$ & 0.038 & $\begin{array}{l}0.011 \\
0.089\end{array}$ & $\begin{array}{l}0.279 \\
0.241^{\star \star}\end{array}$ & 0.125 \\
\hline$s$ & $\begin{array}{l}M S \\
F\end{array}$ & $\begin{array}{l}0.782 \\
3.529^{\star}\end{array}$ & $\begin{array}{l}0.279 \\
1.259\end{array}$ & 0.221 & $\begin{array}{l}1.446 \\
4.955^{\star}\end{array}$ & $\begin{array}{l}1.144 \\
3.920^{\star \star}\end{array}$ & 0.292 \\
\hline K & $\begin{array}{l}M S \\
F\end{array}$ & $\begin{array}{l}0.324 \\
2.400\end{array}$ & $\begin{array}{l}0.104 \\
0.768\end{array}$ & 0.135 & $\begin{array}{l}0.204 \\
0.757\end{array}$ & $\begin{array}{l}0.702 \\
2.609^{\star \star}\end{array}$ & 0.269 \\
\hline $\mathrm{Na}$ & $\begin{array}{l}M S \\
F\end{array}$ & $\begin{array}{l}0.0326 \\
6.173^{\star \star}\end{array}$ & $\begin{array}{l}0.0084 \\
1.591^{\star}\end{array}$ & 0.0053 & $\begin{array}{c}1.045 \\
31.089^{\star \star}\end{array}$ & $\begin{array}{l}0.723 \\
2.151^{\star}\end{array}$ & 0.336 \\
\hline$N$ & $\begin{array}{l}M S \\
F\end{array}$ & $\begin{array}{l}0.072 \\
1.543\end{array}$ & $\begin{array}{l}0.043 \\
0.910\end{array}$ & 0.047 & $\begin{array}{l}0.136 \\
2.647\end{array}$ & $\begin{array}{l}0.0761 \\
1.482\end{array}$ & 0.0513 \\
\hline$G$ & $\begin{array}{l}M S \\
F\end{array}$ & $\begin{array}{l}0.00027 \\
1.130\end{array}$ & $\begin{array}{l}0.00033 \\
1.378\end{array}$ & 0.00024 & $\begin{array}{l}0.00012 \\
1.572\end{array}$ & $\begin{array}{l}0.00020 \\
2.672^{\star \star}\end{array}$ & 0.00007 \\
\hline Ms & $\begin{array}{l}M S \\
F\end{array}$ & $\begin{array}{l}0.018 \\
1.885\end{array}$ & $\begin{array}{l}0.011 \\
1.123\end{array}$ & 0.0095 & $\begin{array}{l}0.0102 \\
0.569\end{array}$ & $\begin{array}{l}0.0255 \\
1.422\end{array}$ & 0.0179 \\
\hline
\end{tabular}

$1990=\mathrm{df}$ for replicates 2 , for varieties $46 ; 1991=\mathrm{df}$ for replicates 2, for varieties 24 ; * significant at the 0.05 level; ** significant at the 0.01 level.

Table IV. Analysis of covariance and values for genotypic correlations $\left(r_{G}\right)$ and micro environmental correlations (residual) $\left(r_{\mathrm{e}}\right)$ for conductivity and polarimetric sugar $(S), \mathrm{K}^{+}(\mathrm{K}), \mathrm{Na}^{+}(\mathrm{Na}), \alpha$-amino nitrogen $(\mathrm{N})$, glucose (G) and molasse sugar (Ms). MP: mean product. $r_{\mathrm{e}}$ and $r_{\mathrm{G}}$ computed from MP (table IV) and MS (table III).

\begin{tabular}{|c|c|c|c|c|}
\hline & \multicolumn{2}{|c|}{ MP } & \multirow[t]{2}{*}{$r_{e}$} & \multirow[t]{2}{*}{$r_{G}$} \\
\hline & Var & Error & & \\
\hline$S$ & -0.3820 & -0.1358 & -0.711 & -0.678 \\
\hline$K$ & 0.3411 & 0.1571 & 0.857 & 0.711 \\
\hline $\mathrm{Na}$ & 0.0590 & 0.0042 & 0.064 & 0.709 \\
\hline$N$ & 0.0682 & 0.0650 & 0.812 & 0.051 \\
\hline$G$ & -0.0048 & 0.0003 & 0.105 & -1.150 \\
\hline$M s$ & 0.0561 & 0.0390 & 0.824 & 0.499 \\
\hline
\end{tabular}

$\mathrm{C} \times \mathrm{Na}, r_{\mathrm{G}}$ positive and high, $r_{\mathrm{e}}$ near zero;

$C \times N, r_{\mathrm{G}}$ near zero, $r_{\mathrm{e}}$ positive and high;

$C \times G, r_{\mathrm{G}}$ negative and very high, $r_{\mathrm{e}}$ very low;

$C \times M s, r_{\mathrm{G}}$ positive and medium, $r_{\mathrm{e}}$ positive and high.

\section{DISCUSSION}

In the experiments reported here conductivity was negatively associated with polarimetric sugar at the phenotypic level $(r=-0.34$ and -0.59$)$ as well as at the micro environmental level (residual) $\left(r_{\mathrm{e}}=-0.71\right)$ and genotypic level $\left(r_{\mathrm{G}}=-0.68\right)$ (tables I, IV).

As was to be expected, conductivity was positively associated with 2 important components of molasses sugar $\mathrm{K}^{+}$and $\mathrm{Na}^{+}$(tables I, II). $\mathrm{K}$ was the first independent trait in the regression equation of $C$, for both years. $\mathrm{Na}$ appeared among the significant variables in 1990 only. The genotypic contribution of $K$ and $\mathrm{Na}$ to $\mathrm{C}$ was relatively high (table IV). The cation concentration had a direct influence on conductivity.

The association of conductivity with the 2 other components is more surprising. The $\alpha$-aminonitrogen was positively correlated with conductivity for both years at the phenotypic level (table I). It was the 3rd independent variable in the multiple regression equation of the 1991 trial. But the genotypic correlation was zero. The association with glucose was negative. Glucose appeared both years in the regression equation. The geno- 
typic correlation was negative but had a high absolute value.

The correlation between conductivity and molasse sugar was somewhat disappointing when compared with the results of Rearick and Schoenrock (1985). The phenotypic correlation was positive for both years but moderate $(0.34<$ $r<0.74)$. The varieties were not significantly different for that trait in either year. Microenvironmental correlation was positive and high. Genotypic correlation was also positive, but medium.

Two explanations may be given for the apparently better results obtained by Rearick and Schoenrock: 1) they have computed a correlation between conductivity and purity - which is the ratio of sucrose to total soluble solids - and not between conductivity and molasse sugar - which is estimated by a formula where a different weight is given to each compound analysed; 2) their samples were from many fields with varied soil fertility and crop management.

For the plant breeder it is the contribution of the genotype to the correlations that matters. From the values computed for genotypic correlations it is clear that selection for low conductivity would result in: 1) an increase in polarimetric sugar; 2) a decrease in $\mathrm{K}^{+}$and $\mathrm{Na}^{+}$concentration; 3) an increase in glucose; and 4) a low decrease in molasse sugar. If the decrease in $\mathrm{K}^{+}$and $\mathrm{Na}^{+}$is good for quality, the increase in glucose is bad.

It is clear that electrolytic conductivity is of interest for the improvement of sugar extractability if we deal with genotypes that are very variable for the purity components, especially $\mathrm{K}+$ and $\mathrm{Na}^{+}$, or if they are grown in an environment favourable to the expression of their genetic variability for quality (Smith et al, 1973).

This very simple and cheap measurement could also prove useful when selection is per- formed among genotypes grown in the presence of a disease like rhizomania, that increases sugar impurity in susceptible genotypes (Richard-Molard, 1987).

\section{ACKNOWLEDGMENTS}

The authors thank A Carteron for his help with the statistics.

\section{REFERENCES}

Berding N, Brotherton GA, Le Brock DG, Skinner JC (1991) Near infrared reflectance spectroscopy for analysis of sugarcane from clonal evaluation trials: I. Fibrated cane. Crop Sci 31, 1017-1023

Bruandet D, Dethune E, Jaouen V, Noe B (1990) Variabilité du critère qualitatif $\mathrm{Sm} \%$ sucre à partir de l'étude des champs d'essais variétés de I'IRIS en 1989. Sucr Fr 143, 13-15

Devillers P (1988) Prévision du sucre mélasse. Sucr Fr 123, 87

Gallais A (1989) Théorie de la sélection en amélioration des plantes. Masson, Paris, 93

Rearick DE, Schoenrock KWR (1985) La conductivité comme indicateur de la qualité de la betterave. In: E-1: 23rd ASSBT Congr San Diego (transl into French)

Richard-Molard M (1987) Variétés tolérantes à la rhizomanie. Résultats d'essais, problèmes posés par leur utilisation. 50th IIRB Winter Congr Rep II, 111130

Smith GA, Hecker RJ, Maag GW, Rasmuson DM (1973) Combining ability and gene action estimates in an eight-parent diallel cross of sugar beet. Crop Sci 13, 312-316

Smith GA, Martin SS, Ash KA (1977) Path coefficient analysis of sugar beet purity components. $\mathrm{Crop} \mathrm{Sci}$ $17,249-253$ 